\title{
Archivos

\section{Receptor de rianodina, fuga de calcio y arritmias}

\author{
Angélica Rueda ${ }^{a, *}$, David R. de Alba-Aguayo ${ }^{a}$ y Héctor H. Valdivia ${ }^{b}$ \\ a Departamento de Bioquímica, Centro de Investigación y de Estudios Avanzados del IPN, Unidad Zacatenco, México D.F., México \\ b Center for Arrhythmia Research, University of Michigan, Ann Arbor, MI, Estados Unidos
}

Recibido el 30 de julio de 2013; aceptado el 2 de diciembre de 2013

\author{
PALABRAS CLAVE \\ Receptor de \\ rianodina; \\ Corazón; \\ Arritmias; \\ Fuga de calcio; \\ Chispas de calcio; \\ México
}

\section{KEYWORDS}

Ryanodine receptor;

Heart;

Arrhythmia;

Calcium leak;

Calcium sparks;

Mexico

\begin{abstract}
Resumen La participación del canal de $\mathrm{Ca}^{2+} /$ receptor de rianodina en el acoplamiento excitación-contracción cardiaco se conoce desde finales de los años ochenta, cuando en varios trabajos trascendentales se comunicó por primera vez su purificación y se encontró que correspondía a las estructuras conocidas como «pies» localizadas en las cisternas terminales del retículo sarcoplásmico. Adicionalmente a su papel como canal responsable del aumento global y transitorio de $\mathrm{Ca}^{2+}$ que activa a la maquinaria contráctil durante el ciclo cardiaco, el receptor de rianodina también libera $\mathrm{Ca}^{2+}$ durante la fase de relajación, dando lugar a la fuga de $\mathrm{Ca}^{2+}$ en la diástole que en condiciones fisiológicas regula el nivel de $\mathrm{Ca}^{2+}$ luminal, pero cuando se encuentra alterada participa en la generación de arritmias adquiridas o hereditarias. Recientemente, el esfuerzo de diversos grupos de investigación se ha enfocado en el desarrollo de herramientas farmacológicas para controlar la fuga diastólica de $\mathrm{Ca}^{2+}$ que se presenta alterada en algunas enfermedades cardiacas. En esta revisión nos enfocamos en describir la participación del receptor de rianodina cardiaco en la fuga diastólica de $\mathrm{Ca}^{2+}$ así como los diversos enfoques terapéuticos que se han implementado para controlar su actividad exacerbada en la diástole. (c) 2013 Instituto Nacional de Cardiología Ignacio Chávez. Publicado por Masson Doyma México S.A. Todos los derechos reservados.
\end{abstract}

\section{Ryanodine receptor, calcium leak and arrhythmias}

Abstract The participation of the ionic $\mathrm{Ca}^{2+}$ release channel/ryanodine receptor in cardiac excitation-contraction coupling is well known since the late ' $80 \mathrm{~s}$, when various seminal papers communicated its purification for the first time and its identity with the "foot" structures located at the terminal cisternae of the sarcoplasmic reticulum. In addition to its main role as the $\mathrm{Ca}^{2+}$ channel responsible for the transient $\mathrm{Ca}^{2+}$ increase that activates the contractile machinery of the cardiomyocytes, the ryanodine receptor releases $\mathrm{Ca}^{2+}$ during the relaxation phase of the cardiac cycle, giving rise to a diastolic $\mathrm{Ca}^{2+}$ leak. In normal physiological conditions,

\footnotetext{
* Autor para correspondencia: Av. IPN 2508, Col. San Pedro Zacatenco, C.P. 07360, México DF, México. Teléfono: +55 5747 3800 Ext. 5215 ; fax: +55 5747339 .

Correo electrónico: arueda@cinvestav.mx (A. Rueda).
} 
diastolic $\mathrm{Ca}^{2+}$ leak regulates the proper level of luminal $\mathrm{Ca}^{2+}$, but in pathological conditions it participates in the generation of both, acquired and hereditary arrhythmias. Very recently, several groups have focused their efforts into the development of pharmacological tools to control the altered diastolic $\mathrm{Ca}^{2+}$ leak via ryanodine receptors. In this review, we focus our interest on describing the participation of cardiac ryanodine receptor in the diastolic $\mathrm{Ca}^{2+}$ leak under physiological or pathological conditions and also on the therapeutic approaches to control its undesired exacerbated activity during diastole.

(C) 2013 Instituto Nacional de Cardiología Ignacio Chávez. Published by Masson Doyma México S.A. All rights reserved.

\section{Introducción}

El ion calcio $\left(\mathrm{Ca}^{2+}\right)$ es el mensajero más importante en el músculo cardiaco, ya que participa activamente en diversos procesos celulares tales como la expresión génica, la diferenciación y la apoptosis, además de ser componente indispensable del proceso de contracción, tal como lo mostró Sidney Ringer ${ }^{1}$. Las fluctuaciones periódicas en la concentración intracelular de $\mathrm{Ca}^{2+}\left(\left[\mathrm{Ca}^{2+}\right]_{\mathrm{i}}\right)$ de los cardiomiocitos determinan en gran medida la magnitud y la duración de la fuerza contráctil. La serie de eventos exquisitamente coordinados mediante los cuales el potencial de acción cardiaco genera un aumento global y transitorio en la $\left[\mathrm{Ca}^{2+}\right]_{i}$ que alcanza niveles de entre 0.6 a $3 \mu \mathrm{M}$ en la sístole y que permite la contracción subsecuente de los miocitos cardiacos se engloban en lo que conocemos como acoplamiento excitación-contracción (AEC), visualizado inicialmente por A. J. Brady ${ }^{2}$ y descrito con mucha más precisión por Fabiato ${ }^{3,4}$.

\section{Participación del receptor de rianodina en el acoplamiento excitación-contracción}

Durante el AEC cardiaco la activación en el cardiomiocito de los canales de $\mathrm{Na}^{+}$dependientes de voltaje $\left(I_{\mathrm{Na}}\right)$ activa a su vez los canales de $\mathrm{Ca}^{2+}$ dependientes de voltaje tipo $\mathrm{L} 0$ receptores a dihidropiridinas (DHPR, por sus siglas en inglés) localizados en una región muy especializada de la membrana plasmática conocida como túbulo T (fig. 1), lo que genera una corriente entrante de $\mathrm{Ca}^{2+}\left(I_{\mathrm{Ca}}\right)$ que por sí sola es insuficiente para inducir la activación de la maquinaria contráctil pero es necesaria para activar al receptor de rianodina (RyR), que en realidad es un canal liberador de $\mathrm{Ca}^{2+}$ del retículo sarcoplásmico de unión (RSU). Este proceso se conoce como liberación de $\mathrm{Ca}^{2+}$ inducida por $\mathrm{Ca}^{2+}(\mathrm{CICR})$, y fue descrito por Fabiato ${ }^{4}$ para el músculo cardiaco, pero definido inicialmente por Endo et al. ${ }^{5}$ en el músculo esquelético.

El $\mathrm{Ca}^{2+}$ liberado vía el RyR se une a la troponina C de los miofilamentos, lo que genera un cambio conformacional en el complejo de la troponina que libera el sitio de interacción miosina-actina y con gasto de ATP se activa la maquinaria contráctil. Para que la relajación ocurra durante el ciclo cardiaco y la $\left[\mathrm{Ca}^{2+}\right]_{i}$ disminuya a su nivel diastólico $(\sim 100 \mathrm{nM})$, se requiere re-secuestrar el $\mathrm{Ca}^{2+}$ liberado por el
RyR mediante la activación de la bomba ATPasa de $\mathrm{Ca}^{2+}$ del retículo sarco/endoplásmico (SERCA), mientras que el $\mathrm{Ca}^{2+}$ que entró como $I_{C a}$ debe ser extruido por el intercambiador $\mathrm{Na}^{+} / \mathrm{Ca}^{2+}$ de la membrana plasmática. Ambas actividades combinadas remueven hasta el $98 \%$ del $\mathrm{Ca}^{2+}$ citoplasmático. La contribución de la bomba ATPasa de la membrana plasmática y del uniportador de $\mathrm{Ca}^{2+}$ mitocondrial en la remoción del $\mathrm{Ca}^{2+}$ citoplasmático es minoritaria (solo $\sim 1 \%$ del $\mathrm{Ca}^{2+}$ total $)^{6}$.

Siendo el $\mathrm{Ca}^{2+}$ el agonista fisiológico del RyR, la salida masiva de $\mathrm{Ca}^{2+}$ de los reservorios intracelulares durante el proceso de CICR implicaría la existencia de un mecanismo de retroalimentación positiva que mantendría activado al RyR de forma permanente (presencia de $\mathrm{Ca}^{2+}=$ activación del RyR). Sin embargo, la fase de diástole del ciclo cardiaco depende de la regulación precisa del RyR y de su inactivación aun en presencia de niveles elevados de $\mathrm{Ca}^{2+}$ en el citoplasma para permitir la recuperación de la $\left[\mathrm{Ca}^{2+}\right]_{i}$ al nivel nanomolar $(\sim 100 \mathrm{nM})$. Las alteraciones en el manejo de $\mathrm{Ca}^{2+}$ sistólico ${ }^{7,8}$ y diastólico ${ }^{9,10}$ del cardiomiocito pueden participar en la disfunción contráctil y en la generación de algunas arritmias. De ahí la importancia de estudiar los mecanismos que participan en la regulación del RyR.

Debido a que la activación del RyR cardiaco es en esencia autorregenerativa $^{11}$, esta requiere de uno o varios mecanismos de inactivación que dependen en gran medida de la presencia de iones y metabolitos citoplasmáticos ${ }^{12,13}$ (como $\mathrm{Ca}^{2+}, \mathrm{Mg}^{2+}$ y ATP), de proteínas reguladoras (calmodulina $^{14}$, sorcina ${ }^{15}$, FKBP12.6 ${ }^{16,17}$, S100A, junctina, triadina y calsecuestrina ${ }^{18,19}$, entre muchas otras), de modificaciones postraduccionales (como fosforilación ${ }^{16,20-22}$, oxidorreducción ${ }^{23}$, S-nitrosilación ${ }^{24}$ y carbonilación ${ }^{25}$ ), así como de la distribución y localización espacial de los RyR en el cardiomiocito ${ }^{26,27}$. Los mecanismos moleculares de regulación endógena del RyR cardiaco han sido sujeto de numerosas y excelentes revisiones ${ }^{28-33}$.

Dentro de los procesos que pueden participar en la terminación de la liberación de $\mathrm{Ca}^{2+}$ vía el RyR se han postulado a: 1) la inactivación/adaptación del RyR dependiente de $\mathrm{Ca}^{2+}$, que involucra al $\mathrm{Ca}^{2+}$ tanto de lado del citoplasma como de la región luminal del $\mathrm{RS}^{34}$ y a proteínas cuya actividad sobre el RyR depende de $\mathrm{Ca}^{2+}$, como sorcina ${ }^{35,36}$, calmodulina ${ }^{14} \mathrm{y}$ calsecuestrina $^{18,19}$; 2) el decaimiento espontáneo de la actividad de los RyR debido al cerrado estocástico del canal (stochastic attrition) ${ }^{37}$; 3) el agotamiento de las reservas de $\mathrm{Ca}^{2+}$ luminal del RS que induce la desactivación del RyR ${ }^{11,19}$, 


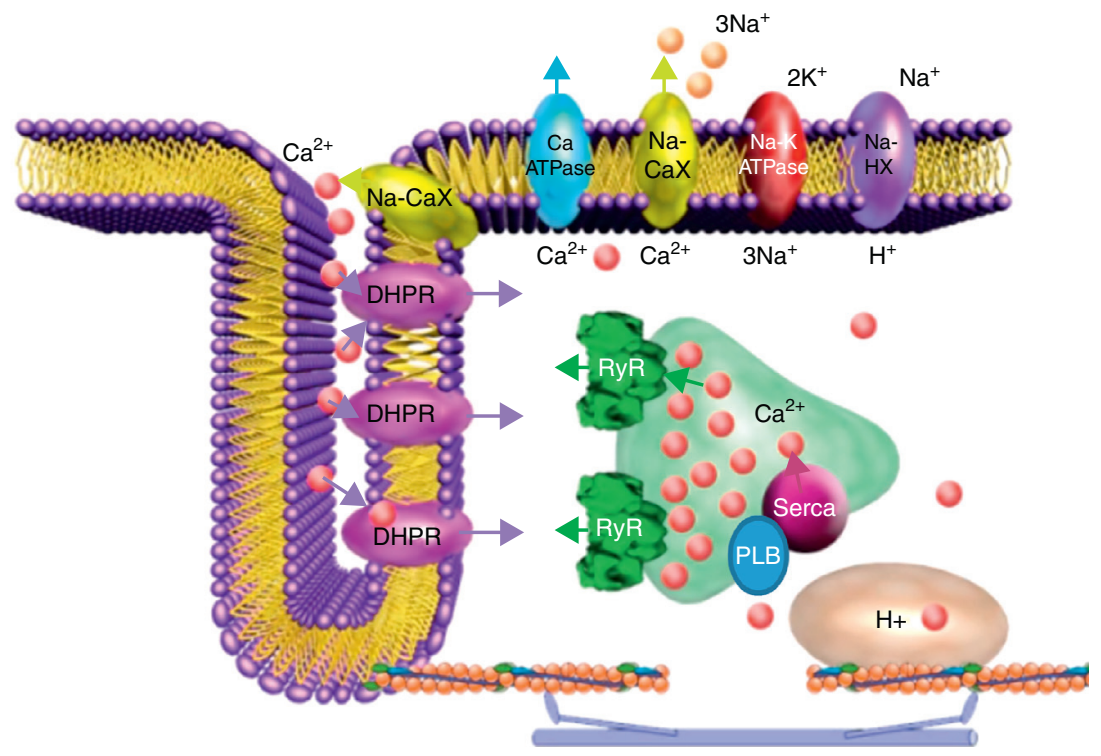

Figura 1 Participación del receptor de rianodina en el acople excitación-contracción cardiaco. El influjo de Ca ${ }^{2+}$ vía los canales de $\mathrm{Ca}^{2+}$ dependientes de voltaje tipo $\mathrm{L}$ o receptores a dihidropiridinas (DHPR, localizados principalmente en los túbulos $T$ ) activa a los receptores de rianodina (RyR) localizados en el RSU, lo que induce la liberación de cantidades mayores de $\mathrm{Ca}^{2+}$ de los reservorios intracelulares aumentando rápidamente la concentración citoplasmática de $\mathrm{Ca}^{2+}$. Esto permite que se active la maquinaria contráctil. Durante la relajación se promueve el cerrado del RyR y la remoción de $\mathrm{Ca}^{2+}$ se lleva a cabo principalmente por la bomba ATPasa de $\mathrm{Ca}^{2+}$ del RS (SERCA), cuya función está regulada por fosfolamban (PLB) y que se encarga de recuperar los reservorios para el siguiente ciclo del AEC; el intercambiador $\mathrm{Na}^{+} / \mathrm{Ca}^{2+}(\mathrm{Na}-\mathrm{CaX})$ remueve parte del $\mathrm{Ca}^{2+}$ hacia al exterior de la célula, y de forma minoritaria la bomba de $\mathrm{Ca}^{2+}$ de la membrana plasmática (Ca-ATPase). Las flechas indican la dirección de los flujos de Ca ${ }^{2+}$ vía los canales iónicos (DHPR, RyR), intercambiadores ( $\mathrm{Na}-\mathrm{CaX}$ ) y bombas (SERCA, Ca-ATPase). Na-K ATPase, bomba ATPasa de $\mathrm{Na}^{+}$y K $\mathrm{K}^{+}$; $\mathrm{Na}-\mathrm{HX}$, intercambiador $\mathrm{Na}^{+} / \mathrm{H}^{+}$.

y por último 4) el «decaimiento inducido» de la actividad de los RyR, una propiedad intrínseca a la microdistribución y activación estocástica de los RyR que permite el aumento y la disolución casi instantánea de los gradientes de $\mathrm{Ca}^{2+}$ nanoscópicos dentro de una región local ${ }^{27}$. Esta última propuesta viene a formar parte de las teorías de control local de la liberación de $\mathrm{Ca}^{2+}$ durante el AEC cardiaco ${ }^{38}$ que han ayudado a explicar cómo un fenómeno en esencia autorregenerativo como el de CICR puede ser limitado espacial y temporalmente para permitir una liberación gradual del $\mathrm{Ca}^{2+}$ del RS durante la sístole. Actualmente no se ha encontrado un mecanismo de terminación de la liberación de $\mathrm{Ca}^{2+}$ vía el RyR lo suficientemente eficiente que permita explicar el cerrado preciso del canal durante el AEC cardiaco ${ }^{11,27}$. Aunque es posible que varios de los mecanismos mencionados funcionen en unísono, se ha propuesto que la inactivación de los RyR dependiente de $\mathrm{Ca}^{2+}$ luminal juega un papel preponderante como mecanismo para detener la naturaleza autorregenerativa inherente al fenómeno de $\mathrm{CICR}^{34}$.

\section{Distribución espacial y regulación in situ de los receptores de rianodina cardiacos}

Algunas de las teorías actuales para explicar la terminación de la salida de $\mathrm{Ca}^{+}$de los reservorios intracelulares - como la del «decaimiento inducido» de la actividad del $\mathrm{Ry}^{27}$ - requieren como premisa una distribución precisa de estos canales iónicos; de ahí la importancia de estudiar la microarquitectura de las diadas, o regiones de acoplamiento entre los RyR que se encuentran en el RSU y los DHPR del túbuloT (fig. 1).

El RyR cardiaco es el canal iónico más grande conocido hasta el momento. El canal funcional es un tetrámero, cada monómero está constituido por 4,967 residuos de aminoácidos (RyR2-human entry: Q92736, http: / / www.uniprot.org) y aparece como una banda prominente, con un peso molecular (Mr) en geles desnaturalizantes (SDS-PAGE) de 340,000 y en ocasiones acompañada de una banda de menor tamaño (Mr de 300,000$)^{39}$, aunque esto último varía dependiendo de las condiciones en que se preparan las vesículas enriquecidas de RS que contienen mayoritariamente al RyR, o bien de las condiciones del SDS-PAGE. Aunque es un solo gen el que codifica a la isoforma cardiaca del RyR (RYR2, localizado en el cromosoma 1 del humano, locus 1q43) ${ }^{40}$, este cuenta con 105 exones que por procesamiento alternativo del mRNA pueden generar por lo menos 2 variantes del RyR2. Estas variantes tienen capacidades diferentes en la regulación del $\mathrm{Ca}^{2+}$ intracelular y de la apoptosis ${ }^{41}$. Gracias al alcaloide rianodina (proveniente de la planta Ryania speciosa) se pudo purificar ${ }^{39,42}$ y determinar la localización subcelular del receptor, el cual se encuentra principalmente en la región del RSU (o cisternas terminales), precisamente donde se encontraban las estructuras conocidas como «pies», que por su tamaño relativamente grande $(210-220 \AA$ por lado) podían ser visualizadas por microscopia electrónica, lo que permitió determinar la identidad molecular de estas estructuras ${ }^{39,42-44}$. 
Datos recientes de microscopia óptica de alta resolución muestran que los RyRs cardiacos del RSU se encuentran formando grupos («racimos» o clústers) dentro de las unidades de liberación de $\mathrm{Ca}^{2+}$ (o CRU, de calcium release units) ${ }^{26,45}$. Los RyR agrupados presentan un arreglo cuasi-cristalino en la región del RSU y se distribuyen de forma regular formando filas dobles con un ancho aproximado de $700 \mathrm{~nm}$ con muy pocos RyR en las regiones intermedias. Dentro de la CRU hay una distancia de 10 a $15 \mathrm{~nm}$ entre los RyR y los DHPR, lo que permite su interacción cercana ${ }^{26}$. Interesantemente, los clústers de RyR varían en forma y tamaño, existiendo en arreglos de entre 14 hasta 22 RyR dentro de cada uno. Un pequeño porcentaje de clústers cuenta con 100 RyR (es posible determinar el número de RyR asumiendo un área de $900 \mathrm{~nm}^{2}$ por canal para dividir el área de cada grupo). Esta organización sigue una distribución que se ajusta a un decaimiento monoexponencial, sugiriendo que la formación del clústers es un proceso estocástico y no altamente regulado, como se creía anteriormente ${ }^{26}$. La distancia entre los RyR dentro del clúster ha sido calculada en $30 \mathrm{~nm}$ a partir del centro del poro, sugiriendo que se encuentran interactuando físicamente, mientras que entre grupos adyacentes de RyR la distancia de borde a borde es de entre 50 a $100 \mathrm{~nm}$, lo que sugiere que la comunicación intragrupo está más favorecida ${ }^{26}$. Por otra parte, en 2006 Sobie et al. ${ }^{46}$ postularon la existencia de RyR que se encuentran fuera de los clústers, conocidos también como «RyRs rebeldes» (rogue RyRs), cuya presencia ha sido confirmada con la microscopia óptica de alta resolución ${ }^{26}$ en zonas del RS clásicamente conocidas como RS corbular ${ }^{44}$, y que son regiones del RSU que contienen RyR pero que no están asociadas al túbulo $T$ o a la membrana plasmática.

Dentro de las CRU, los RyR y los canales de $\mathrm{Ca}^{2+}$ dependientes de voltaje se distribuyen en regiones de $\sim 100 \mathrm{~nm}$ de diámetro. La organización de los RyR y los canales de $\mathrm{Ca}^{2+}$ dependientes de voltaje en las CRU tiene implicaciones biofísicas importantes en cuanto a su funcionalidad en la señalización de $\mathrm{Ca}^{2+}$, y en principio un solo canal de $\mathrm{Ca}^{2+}$ dependiente de voltaje puede activar hasta 5 RyR ${ }^{47-49}$. Recientemente se propuso un modelo donde cada CRU contiene un clúster principal de RyR, que se puede dividir en subdominios funcionales, rodeado por RyR rebeldes, con acceso compartido a un mismo reservorio de $\mathrm{Ca}^{2+}$ luminal; este modelo puede ayudar a explicar la existencia de las diferentes modalidades de liberación espontánea de $\mathrm{Ca}^{2+}$ del RS en condiciones pasivas, como las chispas de $\mathrm{Ca}^{2+}$ y las ondas de $\mathrm{Ca}^{2+}$, que forman parte de lo que conocemos como «fuga de $\mathrm{Ca}^{2+}$ diastólica» ${ }^{46}$.

\section{Participación del receptor de rianodina en la fuga de $\mathrm{Ca}^{2+}$ diastólica}

Bajo condiciones fisiológicas, la activación del RyR durante el AEC cardiaco genera un incremento del $\mathrm{Ca}^{2+}$, homogéneo y transitorio, en el citoplasma del cardiomiocito ${ }^{6,50}$. Sin embargo, en la diástole, al contrario de lo que se pensaba, el RyR no permanece completamente cerrado, sino que puede participar en la liberación de $\mathrm{Ca}^{2+}$ del $\mathrm{RS}$ conocida como fuga de $\mathrm{Ca}^{2+}$ diastólica ${ }^{46}$, la cual está presente en condiciones fisiológicas normales y sufre alteraciones que promueven actividad arrítmica en ciertas afecciones cardiacas.
La fuga de $\mathrm{Ca}^{2+}$ diastólica se puede clasificar en: 1) la mediada por la activación de los RyR dentro de una CRU y que se manifiesta en forma de chispa de $\mathrm{Ca}^{2+}$ (fig. 2); la corriente de $\mathrm{Ca}^{2+}$ de un solo canal de RyR oscila entre 0.35 y $0.6 \mathrm{pA}$ (con una $\left[\mathrm{Ca}^{2+}\right]_{\mathrm{RS}}=1 \mathrm{mM}$ ), y esto implica que para la generación de un evento elemental de liberación de $\mathrm{Ca}^{2+}$ dentro de una CRU (chispa de $\mathrm{Ca}^{2+}$ o $\mathrm{Ca}^{2+}$ spark) es necesaria la apertura sincronizada de por lo menos 6 RyR, aunque el número real es difícil de calcular $^{47-49}$; 2) la que permite el reclutamiento secuencial de CRU adyacentes generando ondas de $\mathrm{Ca}^{2+}$ autopropagadas (fig. 2); si las ondas de $\mathrm{Ca}^{2+}$ activan una corriente transitoria entrante vía el intercambiador $\mathrm{Na}^{+} / \mathrm{Ca}^{2+}$ (Iti), pueden alcanzan el umbral de disparo de un potencial de acción generando actividad automática ${ }^{50,51}$. La actividad automática participa en la generación de arritmias por medio de posdespolarizaciones, que pueden ocurrir dentro (posdespolarizaciones tempranas, o early after depolarizations [EAD]) o después de completar la fase de repolarización del potencial de acción (posdespolarizaciones tardías o delayed after depolarizations $[D A D]$ ), generando contracciones fuera de ritmo (poscontracciones o after contractions); 3) la que no se puede detectar experimentalmente con los microscopios actuales y que está mediada por los RyR rebeldes, conocida como fuga invisible, y por último 4) la mediada por otros canales de la membrana del RS diferentes al RyR (p. ej., el receptor de 1,4,5-trifosfato de inositol) y que son responsables de la fuga de $\mathrm{Ca}^{2+}$ diastólica aun en presencia de altas concentraciones de rojo de rutenio, un inhibidor de los $\mathrm{RyR}^{34,52}$.

La fuga de $\mathrm{Ca}^{2+}$ diastólica que no involucra a los RyR es insensible a las variaciones en la concentración de $\mathrm{Ca}^{2+}$ luminal $\left(\left[\mathrm{Ca}^{2+}\right]_{\mathrm{RS}}\right)$, mientras que la fuga de $\mathrm{Ca}^{2+}$ mediada por los RyR (localizados dentro o fuera de los clústers) es regulada por la $\left[\mathrm{Ca}^{2+}\right]_{\mathrm{RS}}$, por la $\left[\mathrm{Ca}^{2+}\right]_{\mathrm{i}}$ pero no necesariamente por el nivel de fosforilación de los $\mathrm{RyR}^{52,53}$. En condiciones fisiológicas normales, cuando la $\left[\mathrm{Ca}^{2+}\right]_{\mathrm{RS}}$ es relativamente baja $(<400 \mu \mathrm{M})$, la cantidad de $\mathrm{Ca}^{2+}$ liberada por un RyR es insuficiente para generar una chispa, dando lugar a la fuga invisible. Al incrementarse la $\left[\mathrm{Ca}^{2+}\right]_{\mathrm{RS}}(>600 \mu \mathrm{M})$, el flujo de salida de $\mathrm{Ca}^{2+}$ de un RyR es suficiente para que el $\mathrm{Ca}^{2+}$ alcance los sitios de activación por $\mathrm{Ca}^{2+}$ de RyR vecinos, propagándose la activación dentro del clúster, y por tanto la fuga de $\mathrm{Ca}^{2+}$ se presenta en forma de chispas de $\mathrm{Ca}^{2+}$ (fig. 2). Finalmente, en situaciones donde la $\left[\mathrm{Ca}^{2+}\right]_{\mathrm{RS}}$ se incrementa a niveles que alcanzan la sobrecarga del RS, la fuga de $\mathrm{Ca}^{2+}$ mediada por uno o varios clústers puede reclutar clústers adyacentes promoviendo la aparición de ondas de $\mathrm{Ca}^{2+52}$.

En ciertos procesos patológicos donde la fuga de $\mathrm{Ca}^{2+}$ diastólica está alterada, la actividad anormal del RyR genera ondas de $\mathrm{Ca}^{2+}$ que pueden activar al intercambiador $\mathrm{Na}^{+} / \mathrm{Ca}^{2+}$ de la membrana plasmática. Debido a que el intercambiador $\mathrm{Na}^{+} / \mathrm{Ca}^{2+}$ es electrogénico, genera una corriente entrante que si alcanza el umbral de activación de los DHPR promueve DAD, trastorna la función contráctil (al generar extrasístoles) y se manifiesta en arritmias (fig. 3) 34,52-54. Así, la actividad anormal del RyR en la diástole promueve la arritmogénesis vía la generación de ondas de $\mathrm{Ca}^{2+}$ autopropagadas, la activación del intercambiador $\mathrm{Na}^{+} / \mathrm{Ca}^{2+}$ y la aparición de $\mathrm{DAD}^{55-58}$. Es importante mencionar que la fuga de $\mathrm{Ca}^{2+}$ diastólica en forma de chispas que no se propagan a ondas o la mediada por RyR no acoplados 

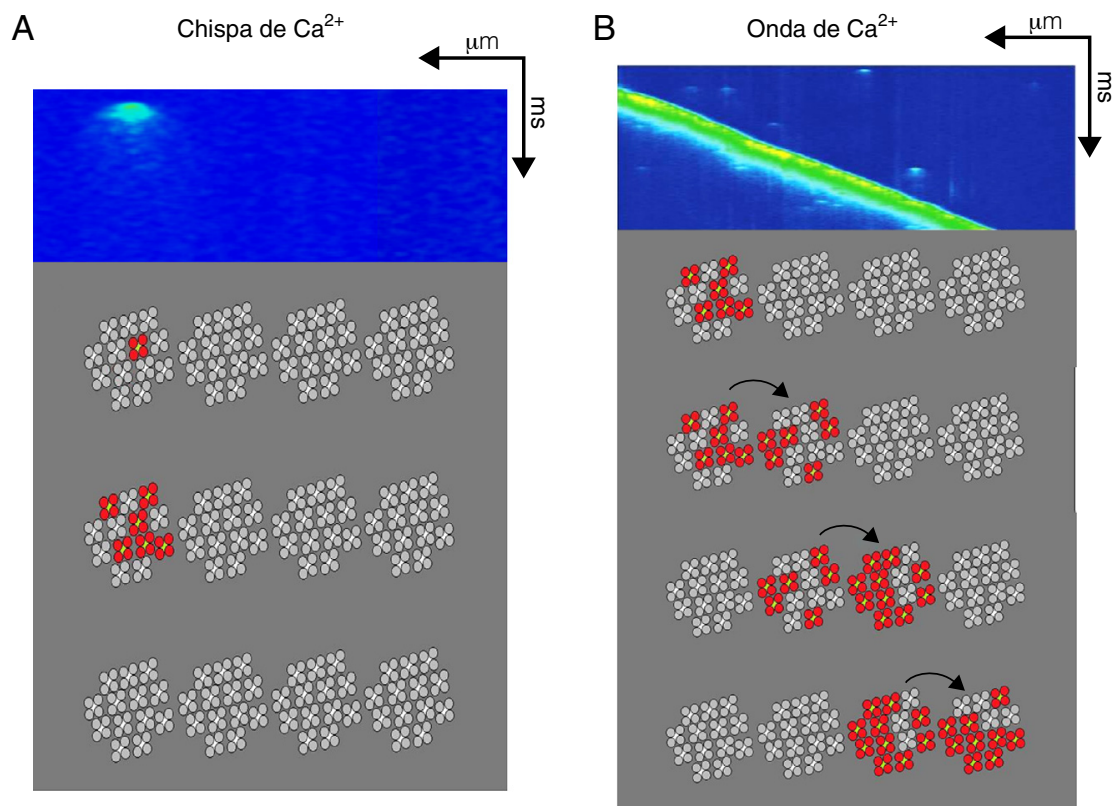

Figura 2 Participación del receptor de rianodina en la fuga de $\mathrm{Ca}^{2+}$ en la diástole. Imágenes bidimensionales obtenidas por microscopia confocal en donde se observa una chispa de $\mathrm{Ca}^{2+}(\mathrm{A})$ y una onda de $\mathrm{Ca}^{2+}$ espontánea (B). En la parte inferior de cada imagen se esquematizan 4 unidades de clústers de RyR con 13 canales iónicos en promedio (tetrámeros en gris claro y centro blanco). La generación de una chispa de $\mathrm{Ca}^{2+}(\mathrm{A})$ requiere la activación cuasisimultánea de al menos 6 RyR (tetrámeros en rojo) dentro de un clúster que generan una señal local de $\mathrm{Ca}^{2+}$ que no propaga a los clústers adyacentes. Por otra parte, las ondas de $\mathrm{Ca}^{2+}$ espontáneas (B) implican la propagación de la señal de $\mathrm{Ca}^{2+}$ a clústers de RyR adyacentes mediante el mecanismo de activación-difusión-activación que pueden generar contracciones fuera del ritmo. Por último, la fuga de $\mathrm{Ca}^{2+}$ que no se puede observar por microscopia confocal (fuga invisible) involucra la apertura de un número reducido (tal vez solo uno) de RyR que pueden localizarse principalmente fuera de los clústers.

(fuga invisible) difícilmente podría promover DAD y, por lo tanto, actividad arritmogénica. El estudio de las propiedades espaciotemporales de las chipas de $\mathrm{Ca}^{2+}$ que se producen de forma espontánea en cardiomiocitos que se encuentran en condiciones en reposo (equivalentes a la diástole) permite conocer cómo los RyR participan en la generación de DAD.

Se ha propuesto que el aumento en la $\left[\mathrm{Ca}^{2+}\right]_{i}$ diastólica $y / o$ en la $\left[\mathrm{Ca}^{2+}\right]_{\mathrm{RS}}$ disminuyen el umbral de activación del RyR, favoreciendo la propagación de ondas de $\mathrm{Ca}^{2+}$
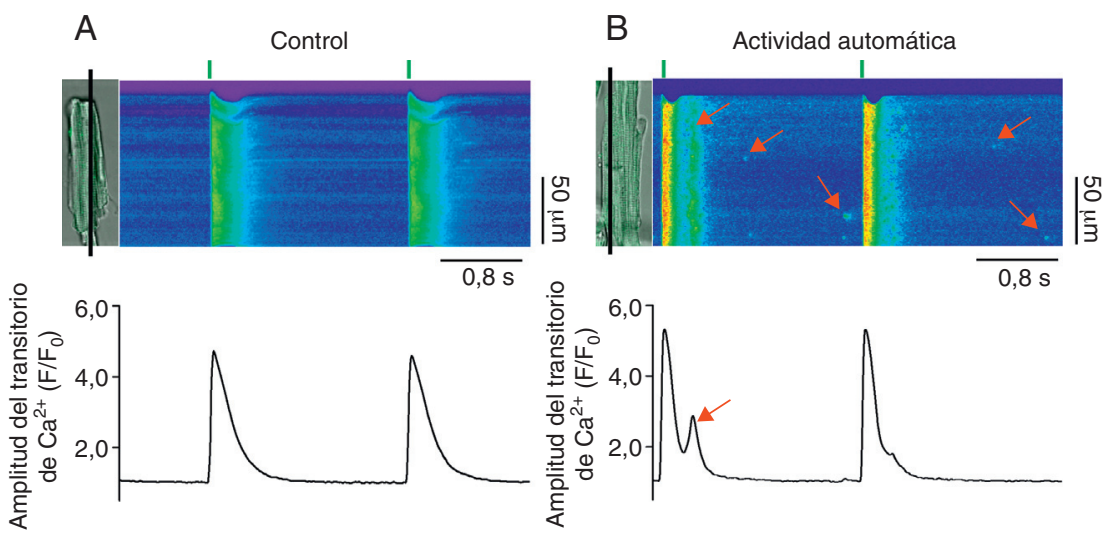

Figura 3 Participación de la fuga diastólica de $\mathrm{Ca}^{2+}$ en la generación de actividad automática. Imágenes representativas de los aumentos transitorios de $\mathrm{Ca}^{2+}$ producidos por estimulación eléctrica $(0.5 \mathrm{~Hz}$, líneas verticales verdes) en cardiomiocitos control (A, control) y con fuga de $\mathrm{Ca}^{2+}$ anormal durante la diástole $(\mathrm{B}$, actividad automática). Las células cargadas con el indicador Fluo3 se escanearon en la modalidad de line-scan en el microscopio confocal (línea negra), lo que permite generar las imágenes bidimensionales donde el ejeX representa el tiempo en segundos y el eje Y representa la longitud de la célula en micrómetros. La amplitud del transitorio de $\mathrm{Ca}^{2+}$ intracelular $\left(\mathrm{F} / \mathrm{F}_{0}\right)$ producido por el estímulo eléctrico se muestra debajo de cada imagen. Las flechas rojas en las imágenes bidimensionales indican la fuga de $\mathrm{Ca}^{2+}$ durante la diástole en forma de chispas de $\mathrm{Ca}^{2+}$ y ondas de $\mathrm{Ca}^{2+}$. 
espontáneas mediante el proceso de activación-difusiónactivación ${ }^{34,52,55}$. Incluso se ha considerado que algunos parámetros de las ondas de $\mathrm{Ca}^{2+}$, tales como la frecuencia, la amplitud y la velocidad de propagación, son predictivos de su potencial arritmogénico ${ }^{34,55,56}$. Sin embargo, paradójicamente existen enfermedades donde la actividad diastólica del RyR está aumentada aun en presencia de una $\left[\mathrm{Ca}^{2+}\right]_{\mathrm{RS}}$ disminuida y que se explican por una mayor sensibilidad del RyR al $\mathrm{Ca}^{2+}$ luminal y/o citoplasmático, que favorecen su activación exacerbada ${ }^{9,57}$. En un estado de alteración crónica el incremento anormal de la fuga de $\mathrm{Ca}^{2+}$ no puede durar por siempre, ya que las células contienen poderosos mecanismos de autorregulación para controlar la actividad anormal de los RyR a largo plazo ${ }^{58}$. Desafortunadamente, los mecanismos moleculares específicos que participan en modificar la fuga de $\mathrm{Ca}^{2+}$ diastólica en ciertas enfermedades cardiacas aún no han sido completamente aclarados.

\section{Función fisiológica de la fuga diastólica de $\mathrm{Ca}^{2+}$ mediada por el receptor de rianodina}

La participación del RyR en inducir una fuga de $\mathrm{Ca}^{2+}$ del RS se evidenció en un trabajo del grupo de Lakatta, en el que se observó que la incubación de cardiomiocitos intactos y en reposo con rianodina a concentraciones nanomolares vaciaba los reservorios intracelulares de $\mathrm{Ca}^{2+}$ localizados en el RS, lo cual se explica por la propiedad de este alcaloide de unirse únicamente a la conformación abierta del canal y de mantenerlo subconductante ${ }^{59}$. Posteriormente, Urthaler et al. ${ }^{60}$ reforzaron la idea de que el RyR fugaba $\mathrm{Ca}^{2+}$ en la diástole al mostrar que la RyR aumentaba esta fuga por inhibir el cerrado de los canales de $\mathrm{Ca}^{2+}$ del RS. Más tarde, Yamazawa et al. ${ }^{61}$ mostraron que la expresión de RyR2 en cultivos primarios de músculo esquelético de ratones dispédicos (es decir, que no expresan al RyR tipo 10 esquelético) inducía chispas de $\mathrm{Ca}^{2+}$ evocadas y ondas de $\mathrm{Ca}^{2+}$ espontáneas a $\left[\mathrm{Ca}^{2+}\right]_{\mathrm{i}}$ basales, sugiriendo que la isoforma cardiaca del RyR se activa a $\left[\mathrm{Ca}^{2+}\right]_{i}$ diastólica y puede mediar la fuga de $\mathrm{Ca}^{2+}$. En 1998, Takeshima et al. ${ }^{62}$ proponen que durante el desarrollo embrionario los RyR2 se activan en la diástole en respuesta a elevaciones en la $\left[\mathrm{Ca}^{2+}\right]_{\mathrm{RS}}$, comportándose como válvulas de seguridad para prevenir la sobrecarga de $\mathrm{Ca}^{2+}$ del RS. Esta hipótesis la plantean al observar que en cardiomiocitos de embriones que carecen del RyR2 el $\mathrm{Ca}^{2+}$ se acumulaba gradualmente dentro de los reservorios del RS induciendo la formación de vacuolas a partir del RS, anormalidades en las mitocondrias y desregulación de la homeostasis del $\mathrm{Ca}^{2+}$, lo que conduce a una disfunción general del cardiomiocito ${ }^{62}$. Sin embargo, la función fisiológica de la fuga de $\mathrm{Ca}^{2+}$ mediada por el RyR no está restringida al corazón en desarrollo, también está presente en el corazón adulto y permite mantener la $\left[\mathrm{Ca}^{2+}\right]_{\mathrm{RS}}$ dentro de un rango normal, como un mecanismo de balance a la actividad de recaptura de la bomba SERCA, permitiendo la estabilización de la actividad del RyR entre latido y latido ${ }^{63,64}$. En cardiomiocitos normales el incremento en la $\left[\mathrm{Ca}^{2+}\right]_{\mathrm{RS}}$ aumenta la frecuencia de las chispas de $\mathrm{Ca}^{2+}$ espontáneas, permitiendo que el RyR2 regule el contenido de $\mathrm{Ca}^{2+}$ del RS a través de la fuga mediada por chispas $^{65}$.

\section{Arritmias relacionadas con alteraciones en la fuga diastólica de $\mathrm{Ca}^{2+}$}

Las arritmias cardiacas asociadas a enfermedades hereditarias o adquiridas son causantes de la morbimortalidad de un gran porcentaje de la población de los países industrializados, como Estados Unidos y México. De las 590,693 defunciones registradas en México en 2011, el $23.8 \%(140,595)$ corresponden a muertes relacionadas con enfermedades cardiovasculares (fuente INEGI), y entre ellas deben estar algunas arritmias, como la fibrilación ventricular.

En ciertas enfermedades cardiacas la fuga de $\mathrm{Ca}^{2+}$ está alterada y participa en la generación de arritmias adquiridas (como las que se presentan en la insuficiencia cardiaca, la miocardiopatía diabética y la fibrilación auricular) o hereditarias (como la taquicardia ventricular polimórfica y catecolaminérgica [TVPC] y la displasia arritmogénica del ventrículo derecho tipo 2 [DAVD2] $)^{66}$. En 2001, 2 grupos de investigadores identificaron un total de 11 mutaciones puntuales en el gen que codifica para el RyR cardiaco, el RYR2, asociadas con la presencia de TVPC en 7 familias diferentes $^{67,68}$ y a DAVD2 en 4 familias independientes ${ }^{69}$. Hasta la fecha se han identificado 128 variantes del hRYR2 y 12 variantes de la calsecuestrina 2 que están asociadas a estas arritmias (http://www.fsm.it/cardmoc/) (0) $^{70}$ lo que ha abierto un nuevo panorama al evidenciar que las alteraciones en la fuga de $\mathrm{Ca}^{2+}$ vía el RyR2 pueden ser parte de las bases moleculares de la arritmogénesis cardiaca.

\section{Mutaciones del receptor de rianodina asociadas a taquicardia ventricular polimórfica y catecolaminérgica}

La TVPC es una arritmia hereditaria que se caracteriza por la aparición de una taquicardia ventricular que puede ser bidireccional o polimórfica inducida por estrés o ejercicio sin presentar alteraciones estructurales del corazón ${ }^{67,68,71}$. En la mayoría de los casos la taquicardia ventricular conduce a fibrilación ventricular y síncope o muerte súbita. Debido a que el electrocardiograma de los pacientes con TVPC no presenta anormalidades en condiciones de reposo, el diagnóstico implica la detección de la arritmia inducida por estrés durante una prueba de ejercicio o Holter. Esta arritmia hereditaria se presenta en 2 formas: dominante y recesiva. La forma dominante de esta arritmia está asociada a mutaciones en el gen $R Y R 2$ que codifica al RyR cardiaco o tipo 2 (RyR2), mientras que la forma recesiva está asociada alteraciones en el gen de la calsecuestrina 2 (CSQ2), proteína que se encuentra en la luz del RS, que tiene una gran capacidad para unir $\mathrm{Ca}^{2+}$ y que participa junto con triadina y junctina en modular la respuesta del RyR al $\mathrm{Ca}^{2+}$ luminal ${ }^{72}$.

Debido a la importancia que tiene el determinar las bases moleculares de las arritmias, se han generado ratones transgénicos que expresan al RyR2 con alguna de las mutaciones puntuales encontradas en TVPC. El ratón knock in heterocigoto para la variante $R y R 2^{R 4497 C}$ recapitula muchas de las características fenotípicas de los pacientes con TVPC, bajo estimulación $\beta$-adrenérgica ${ }^{73}$. Los cardiomiocitos ventriculares del ratón heterocigoto presentan DAD y actividad 
automática en presencia de isoproterenol ${ }^{9}$. En condiciones de reposo existe un aumento en la fuga de $\mathrm{Ca}^{2+}$ diastólica en forma de mayor frecuencia de chispas, el cual se ve exacerbado en presencia de isoproterenol, aun en ausencia de una sobrecarga de $\mathrm{Ca}^{2+}$ del $\mathrm{RS}^{9}$. La actividad anormal del $\mathrm{RyR}^{\mathrm{R} 4497 \mathrm{C}}$ se ha explicado por un incremento exclusivo en su sensibilidad al $\mathrm{Ca}^{2+}$ luminal; sin embargo, esta idea es controversial, debido a que también existe evidencia de que su sensibilidad al $\mathrm{Ca}^{2+}$ del citoplasma esta aumentada, lo que le permite activarse más aun en condiciones de baja $\left[\mathrm{Ca}^{2+}\right]_{\mathrm{RS}^{9}}$. Es posible, entonces, que las mutaciones del RyR2 asociadas con TVPC den lugar a varios fenotipos moleculares arritmogénicos, en lugar de un solo fenotipo (p. ej., incremento a sensibilidad a $\mathrm{Ca}^{2+}$ (uminal). En apoyo a esta hipótesis, una mutación altamente arritmogénica del RyR2 asociada con TVPC, la RyR2 ${ }^{\mathrm{V} 2475 \mathrm{~F}}$, presenta una mayor sensibilidad al $\mathrm{Ca}^{2+}$ citoplasmático y luminal y también respuesta exacerbada a la fosforilación por la cinasa de proteínas dependiente de AMPC (PKA $)^{74}$.

\section{Fuga de $\mathrm{Ca}^{2+}$ en la insuficiencia cardiaca}

La insuficiencia cardiaca (IC) continúa siendo un problema serio de salud en los países industrializados, como México. Las causas de la IC son muy heterogéneas, pero destacan las asociadas a la presencia de cardiomiopatías congénitas, hipertensión arterial, nefropatías, obesidad y diabetes mellitus, entre otras. Las consecuencias funcionales de la IC en la actividad del corazón se manifiestan como disfunción contráctil, actividad arritmogénica y remodelamiento estructural patológico. Parte de la disfunción del corazón en la IC se podría explicar por un aumento de la estimulación simpática y la concomitante liberación de catecolaminas que induce la activación de los receptores $\beta$-adrenérgicos; sin embargo, en los pacientes con IC crónica la respuesta $\beta$-adrenérgica se encuentra abatida. Una observación consistente es que los RyR2 aislados de corazones insuficientes, tanto de humanos como de modelos experimentales, presentan alteraciones en su actividad $\mathrm{a}\left[\mathrm{Ca}^{2+}\right]_{\mathrm{i}}$ en reposo, lo cual se refleja en un aumento de la fuga de $\mathrm{Ca}^{2+}$ diastólica ${ }^{54,75}$, aunque estas alteraciones no necesariamente se reflejan en cambios consistentes en la actividad del RyR en forma de chispas. Por el contrario, cardiomiocitos aislados de diversos modelos experimentales de IC muestran aumento ${ }^{75,76}$, disminución ${ }^{77}$ o ningún cambio evidente ${ }^{7}$ en la fuga de $\mathrm{Ca}^{2+}$ en forma de chispas. Las posibles explicaciones a estas discrepancias pueden encontrarse en diferencias específicas de cada modelo experimental de IC principalmente relacionadas con la modulación in situ del RyR. En estas diferencias encontramos modificaciones postraduccionales (como fosforilación, oxidorreducción y S-nitrosilación), aunado al remodelamiento estructural que altera la distribución de los RyR dentro de las unidades de liberación y que podría favorecer la fuga de $\mathrm{Ca}^{2+}$ vía ondas u oscilaciones de $\mathrm{Ca}^{2+}$ (fig. 2), o vía los RyR «rebeldes» ${ }^{46,54}$. En el año 2000 el grupo de A. Marks ${ }^{16}$ propuso que el aumento de los niveles de catecolaminas en los pacientes con IC activa a la PKA vía los receptores $\beta$-adrenérgicos, lo que induce la «hiperfosforilación» del RyR2 en la Ser2808 y la concomitante disociación de la FKBP12.6. En este esquema, estas modificaciones provocan la actividad descontrolada del RyR, lo que incrementa la fuga de $\mathrm{Ca}^{2+}$ diastólica y la propensión a eventos arrítmicos ${ }^{16,66}$. Sin embargo, diversos grupos de investigación han aportado evidencias que no permiten apoyar esta hipótesis ${ }^{32}$. Por ejemplo, el AMPc incrementa la frecuencia de chispas de $\mathrm{Ca}^{2+}$ en cardiomiocitos permeabilizados con estreptolisina- 0 , pero esto se debe a un aumento en la $\left[\mathrm{Ca}^{2+}\right]_{\mathrm{RS}}$ (por el incremento en la actividad de la bomba SERCA) y no a un efecto directo sobre el RyR y su estado de fosforilación ${ }^{78}$. De hecho, la fosforilación del RyR en la Ser2808 no disocia a la FKBP12.6 ni modifica sustancialmente su actividad $^{32}$; por el contrario, este sitio se ha encontrado constitutivamente fosforilado, independientemente de la presencia o no de IC. Además, estudios recientes en el modelo murino que expresa al RyR ${ }^{\mathrm{S} 2808 \mathrm{~A}}$ en tejido cardiaco - lo que evita la fosforilación de este residuo y por lo tanto, teóricamente, estabiliza la interacción RyR-FKBP12.6 - muestran que los ratones RyR ${ }^{\text {S2808A }}$ presentan una respuesta normal a la estimulación $\beta$-adrenérgica y una progresión similar a la IC comparado con los ratones que expresan al RyR2 normal ${ }^{79,80}$. Estos hallazgos controversiales requieren mucho trabajo adicional para aclarar la participación de la fosforilación del residuo Ser2808 en la fuga de $\mathrm{Ca}^{2+}$ diastólica durante la IC.

Adicionalmente, la activación de los receptores $\beta$ adrenérgicos también induce la fosforilación del RyR vía la cinasa de proteínas dependiente de $\mathrm{Ca}^{2+}$ y calmodulina tipo 2 (CaMKII). Hasta el momento se han identificado 3 sitios de fosforilación en el RyR2 con relevancia fisiológica: la Ser2808, que puede ser fosforilada por PKA o CaMKII; la Ser2814, al parecer exclusivamente fosforilada por CaMKII, y la Ser2030, únicamente fosforilada por $\mathrm{PKA}^{32}$, y no se tiene un consenso sobre cuál de estos sitios promueve el fenotipo que participa en la fuga de $\mathrm{Ca}^{2+}$ alterada. Trabajos muy recientes proponen que la fosforilación del residuo Ser2814 vía CaMKII es fundamental para inducir la fuga de $\mathrm{Ca}^{2+}$ alterada y la actividad arritmogénica en la $I^{81,82}$, por lo que se están acumulando más evidencias que muestran que es la actividad de la CaMKII y no la de la PKA la que favorece la actividad exacerbada del RyR durante la diástole y promueve la arritmogénesis en la IC.

\section{Estrategias farmacológicas para el control de arritmias que involucran al receptor de rianodina}

Debido a las evidencias que muestran que la fuga de $\mathrm{Ca}^{2+}$ diastólica vía los RyR está asociada a la generación de actividad arrítmica, diversos grupos de investigación han dedicado sus esfuerzos al desarrollo de estrategias terapéuticas para reducir la actividad anormal de los RyR ${ }^{83}$. Dentro de los fármacos utilizados encontramos inhibidores de los receptores $\beta$-adrenérgicos como el metoprolol y el carvediol $^{84,85}$, derivados de hidantoínas como el dantroleno ${ }^{86-88}$, derivados del diltiazem como el JTV519 (o K201) y el S107 ${ }^{89-92}$, agentes antiarrítmicos de la clase lc, como la flecainida93-95, y glucósidos de resveratrol como la polidatina ${ }^{96}$; muchos de estos fármacos aún están en fase experimental debido a que existen diversas controversias sobre sus mecanismos de acción, como es el caso del JTV519, por lo que no han sido aprobados para el uso clínico. 
Los bloqueadores de los receptores $\beta$-adrenérgicos disminuyen la fuga de $\mathrm{Ca}^{2+}$ vía el RyR2 al reducir la fosforilación del canal independientemente de si es mediada por PKA o $\mathrm{CaMKII}^{84}$, o bien por cambiar el estado redox del RyR2 al disminuir la oxidación de grupos tiol ${ }^{85}$.

El dantroleno es un relajante muscular utilizado como agente terapéutico en pacientes que padecen hipertermia maligna. El dantroleno se une en la región que corresponde a los aminoácidos 601 a 620 del RyR2 y que conecta los dominios $\mathrm{N}$-terminal y central del canal, y se ha demostrado que corrige la actividad anómala del RyR2 en un modelo de IC en perro $^{86}$. Adicionalmente el dantroleno disminuye la frecuencia de las chispas de $\mathrm{Ca}^{2+}$ espontáneas en cardiomiocitos del ratón que expresan el RyR ${ }^{\mathrm{R} 2474587}$, así como en cardiomiocitos de conejo con IC, aunque en este último caso el dantroleno también indujo un aumento en la $\left[\mathrm{Ca}^{2+}\right]_{\mathrm{RS}}$, lo que podría favorecer una sobrecarga de $\mathrm{Ca}^{2+}$ del $\mathrm{RS}^{88}$.

El JTV519, también llamado K201, es un derivado de la 1-4 benzotiazepina que ha sido propuesto como un posible agente terapéutico para disminuir la fuga de $\mathrm{Ca}^{2+}$ diastólica vía el RyR2 en la IC y en la TVPC al reducir la disociación de la proteína FKPB12.689,90,97. Sin embargo, existen trabajos que muestran que el JTV519 no disminuye la aparición de DAD en un modelo murino de TVPC $^{98}$, además de que su mecanismo de acción es independiente del nivel de fosforilación del RyR o de la cantidad de FKBP12.6 que tenga asociada ${ }^{91,92}$. Adicionalmente, el JTV519 inhibe otros canales iónicos que se expresan en el tejido cardiaco ${ }^{99,100}$, por lo que al tener efectos pleotrópicos su uso como agente antiarrítmico es cuestionable.

La flecainida es un agente antiarrítmico del tipo Ic debido a que su mecanismo de acción involucra la inactivación de los canales de $\mathrm{Na}^{+}$dependientes de voltaje $\left(I_{\mathrm{Na}}\right)$. Recientemente se encontró que la flecainida también reduce la fuga de $\mathrm{Ca}^{2+}$ diastólica en un modelo murino de TVPC ${ }^{94}$, aunque existen opiniones divergentes acerca de si el fármaco actúa directamente en el RyR o bien modula su actividad de forma indirecta al inhibir la $I_{\mathrm{Na}}{ }^{95}$. Incluso existen evidencias de que la flecainida reduce la masa de la chispa de $\mathrm{Ca}^{2+}$ pero a la vez incrementa su frecuencia, por lo que el efecto neto en la fuga de $\mathrm{Ca}^{2+}$ mediada por chispas sería nulo ${ }^{93}$

Recientemente se introdujo la polidatina como un posible agente cardioprotector. La polidatina es un glucósido del resveratrol aislado de la planta Polygonum cuspidatum con potentes efectos antioxidantes. Se ha demostrado que disminuye la fuga de $\mathrm{Ca}^{2+}$ mediada por chispas al reducir los niveles de especies reactivas de oxígeno y restaurar los grupos tioles del RyR2 en cardiomiocitos de animales lesionados por quemaduras ${ }^{96}$. Sin embargo su introducción es muy reciente, por lo que se requieren más estudios para evaluar posibles efectos inespecíficos.

Es importante aclarar que no toda la fuga de $\mathrm{Ca}^{2+}$ diastólica ocurre vía los RyR, ya que existen evidencias de que puede haber otros canales iónicos involucrados. Como ejemplo, recientemente se encontró que la proteína PLB en su forma fosforilada puede aumentar la fuga pasiva de $\mathrm{Ca}^{2+}$ del RS, la cual es resistente al efecto del rojo de rutenio ${ }^{101}$.

Por último, las estrategias terapéuticas futuras deberán evaluar que los posibles fármacos antiarrítmicos no interfieran con la liberación sistólica de $\mathrm{Ca}^{2+}$ en condiciones fisiológicas y que, a su vez, la fuga diastólica no sea completamente suprimida debido a su participación tan importante en la regulación de la $\left[\mathrm{Ca}^{2+}\right]_{\mathrm{RS}}$.

\section{Financiación}

Este trabajo fue apoyado por el Instituto de Ciencia y Tecnología del Distrito Federal (ICyTDF, proyecto No.331/2010) para A. R. y el Instituto Nacional de Salud de EE. UU. (NIH, donativos HL055438 y HL094291) para H.H.V.

\section{Conflicto de intereses}

Los autores declaran no tener ningún conflicto de intereses.

\section{Bibliografía}

1. Ringer S. A further contribution regarding the influence of the different constituents of the blood on the contraction of the heart. J Physiol. 1883;4:29-42.

2. Brady AJ. Excitation and excitation-contraction coupling in cardiac muscle. Annu Rev Physiol. 1964;26:341-56.

3. Fabiato A, Fabiato F. Calcium and cardiac excitationcontraction coupling. Annu Rev Physiol. 1979;41: 473-84.

4. Fabiato A. Calcium-induced release of calcium from the cardiac sarcoplasmic reticulum. Am J Physiol. 1983;245:C1-14.

5. Endo M, Tanaka M, Ogawa Y. Calcium induced release of calcium from the sarcoplasmic reticulum of skinned skeletal muscle fibres. Nature. 1970;228:34-6.

6. Bers D. Cardiac excitation-contraction coupling. Nature. 2002;415:198-205.

7. Gómez AM, Valdivia HH, Cheng H, Lederer MR, Santana LF, Cannell MB, et al. Defective excitation-contraction coupling in experimental cardiac hypertrophy and heart failure. Science. 1997;276:800-6.

8. Pereira L, Matthes J, Schuster I, Valdivia HH, Herzig S, Richard S, et al. Mechanisms of $\left[\mathrm{Ca}^{2+}\right]_{i}$ transient decrease in cardiomyopathy of $\mathrm{db} / \mathrm{db}$ type 2 diabetic mice. Diabetes. 2006;55:608-15.

9. Fernández-Velasco M, Rueda A, Rizzi N, Benitah JP, Colombi B, Napolitano C, et al. Increased $\mathrm{Ca}^{2+}$ sensitivity of the ryanodine receptor mutant RyR2R4496C underlies catecholaminergic polymorphic ventricular tachycardia. Circ Res. 2009;104:201-9, 12p following 9.

10. Gómez A, Rueda A, Sainte-Marie Y, Pereira L, Zissimopoulos $S$, Zhu $\mathrm{X}$, et al. Mineralocorticoid modulation of cardiac ryanodine receptor activity is associated with downregulation of FK506-binding proteins. Circulation. 2009;119:2179-87.

11. Stern M, Cheng H. Putting out the fire: What terminates calcium-induced calcium release in cardiac muscle? Cell Calcium. 2004;35:591-601.

12. Meissner G. Ryanodine receptor $/ \mathrm{Ca}^{2+}$ release channels and their regulation by endogenous effectors. Annu Rev Physiol. 1994;56:485-508.

13. Gillespie D, Chen H, Fill M. Is ryanodine receptor a calcium or magnesium channel? Roles of $\mathrm{K}^{+}$and $\mathrm{Mg}^{2+}$ during $\mathrm{Ca} 2+$ release. Cell Calcium. 2012;51:427-33.

14. Xu L, Meissner G. Mechanism of calmodulin inhibition of cardiac sarcoplasmic reticulum Ca2+ release channel (ryanodine receptor). Biophys J. 2004;86:797-804.

15. Farrell E, Antaramian A, Rueda A, Gómez AM, Valdivia $\mathrm{HH}$. Sorcin inhibits calcium release and modulates excitation-contraction coupling in the heart. J Biol Chem. 2003;278:34660-6. 
16. Marx S, Reiken S, Hisamatsu Y, Jayaraman T, Burkhoff D, Rosemblit N, et al. PKA phosphorylation dissociates FKBP12.6 from the calcium release channel (ryanodine receptor): Defective regulation in failing hearts. Cell. 2000;101:365-76.

17. Gómez AM, Schuster I, Fauconnier J, Prestle J, Hasenfuss G, Richard S. FKBP12.6 overexpression decreases $\mathrm{Ca}^{2+}$ spark amplitude but enhances $\left[\mathrm{Ca}^{2+}\right]_{i}$ transient in rat cardiac myocytes. Am J Physiol Heart Circ Physiol. 2004;287:H1987-93.

18. Terentyev D, Kubalova Z, Valle G, Nori A, Vedamoorthyrao S, Terentyeva R, et al. Modulation of $\mathrm{SR} \mathrm{Ca}^{2+}$ release by luminal $\mathrm{Ca}^{2+}$ and calsequestrin in cardiac myocytes: Effects of CASQ2 mutations linked to sudden cardiac death. Biophys J. 2008;95:2037-48.

19. Györke S, Terentyev D. Modulation of ryanodine receptor by luminal calcium and accessory proteins in health and cardiac disease. Cardiovasc Res. 2008;77:245-55.

20. Shan J, Kushnir A, Betzenhauser MJ, Reiken S, Li J, Lehnart $\mathrm{SE}$, et al. Phosphorylation of the ryanodine receptor mediates the cardiac fight or flight response in mice. J Clin Invest. 2010;120:4388-98.

21. Ullrich ND, Valdivia HH, Niggli E. PKA phosphorylation of cardiac ryanodine receptor modulates SR luminal $\mathrm{Ca}^{2+}$ sensitivity. J Mol Cell Cardiol. 2012;53:33-42.

22. Valdivia HH. Ryanodine receptor phosphorylation and heart failure: Phasing out S2808 and "criminalizing" S2814. Circ Res. 2012;110:1398-402.

23. Terentyev D, Györke I, Belevych AE, Terentyeva R, Sridhar A, Nishijima Y, et al. Redox modification of ryanodine receptors contributes to sarcoplasmic reticulum $\mathrm{Ca}^{2+}$ leak in chronic heart failure. Circ Res. 2008;103:1466-72.

24. Wang H, Viatchenko-Karpinski S, Sun J, Györke I, Benkusky NA, Kohr MJ, et al. Regulation of myocyte contraction via neuronal nitric oxide synthase: Role of ryanodine receptor Snitrosylation. J Physiol. 2010;588:2905-17.

25. Shao CH, Tian C, Ouyang S, Moore CJ, Alomar F, Nemet I, et al. Carbonylation induces heterogeneity in cardiac ryanodine receptor function in diabetes mellitus. Mol Pharmacol. 2012;82:383-99.

26. Baddeley D, Jayasinghe ID, Lam L, Rossberger S, Cannell MB, Soeller C. Optical single-channel resolution imaging of the ryanodine receptor distribution in rat cardiac myocytes. Proc Natl Acad Sci U S A. 2009;106:22275-80.

27. Laver DR, Kong CH, Imtiaz MS, Cannell MB. Termination of calcium-induced calcium release by induction decay: An emergent property of stochastic channel gating and molecular scale architecture. J Mol Cell Cardiol. 2013;54:98-100.

28. Fill M, Copello JA. Ryanodine receptor calcium release channels. Physiol Rev. 2002;82:893-922.

29. Bers D. Macromolecular complexes regulating cardiac ryanodine receptor function. J Mol Cell Cardiol. 2004;37:417-29.

30. Lanner JT, Georgiou DK, Joshi AD, Hamilton SL. Ryanodine receptors: Structure, expression, molecular details, and function in calcium release. Cold Spring Harb Perspect Biol. 2010;2:a003996.

31. Song DW, Lee JG, Youn HS, Eom SH, Kim do H. Ryanodine receptor assembly: A novel systems biology approach to 3D mapping. Prog Biophys Mol Biol. 2011;105:145-61.

32. Capes EM, Loaiza R, Valdivia HH. Ryanodine receptors. Skelet Muscle. 2011;1:18.

33. Meissner G. Molecular regulation of cardiac ryanodine receptor ion channel. Cell Calcium. 2004;35:621-8.

34. Kunitomo Y, Terentyev D. How to stop the fire? Control of $\mathrm{Ca}^{+}$-induced $\mathrm{Ca2}^{+}$release in cardiac muscle. J Physiol. 2011;589:5899-900.

35. Farrell E, Antaramian A, Benkusky N, Zhu X, Rueda A, Gómez $A M$, et al. Regulation of cardiac excitation-contraction coupling by sorcin, a novel modulator of ryanodine receptors. Biol Res. 2004;37:609-12.
36. Rueda A, Song M, Toro L, Stefani E, Valdivia HH. Sorcin modulation of $\mathrm{Ca}^{2+}$ sparks in rat vascular smooth muscle cells. J Physiol. 2006;576:887-901.

37. Sham J, Song L, Chen Y, Deng LH, Stern MD, Lakatta EG, et al. Termination of $\mathrm{Ca}^{2+}$ release by a local inactivation of ryanodine receptors in cardiac myocytes. Proc Natl Acad Sci U S A. 1998;95:15096-101.

38. Cannell MB, Kong CH. Local control in cardiac E-C coupling. J Mol Cell Cardiol. 2012;52:298-303.

39. Inui M, Saito A, Fleischer S. Isolation of the ryanodine receptor from cardiac sarcoplasmic reticulum and identity with the feet structures. J Biol Chem. 1987;262:15637-42.

40. Otsu K, Willard HF, Khanna VK, Zorzato F, Green NM, MacLennan $\mathrm{DH}$. Molecular cloning of cDNA encoding the $\mathrm{Ca}^{2+}$ release channel (ryanodine receptor) of rabbit cardiac muscle sarcoplasmic reticulum. J Biol Chem. 1990;265:13472-83.

41. George CH, Rogers SA, Bertrand BM, Tunwell RE, Thomas NL, Steele DS, et al. Alternative splicing of ryanodine receptors modulates cardiomyocyte $\mathrm{Ca}^{2+}$ signaling and susceptibility to apoptosis. Circ Res. 2007;100:874-83.

42. Inui M, Saito A, Fleischer S. Purification of the ryanodine receptor and identity with feet structures of junctional terminal cisternae of sarcoplasmic reticulum from fast skeletal muscle. J Biol Chem. 1987;262:1740-7.

43. Inui M, Wang S, Saito A, Fleischer S. Characterization of junctional and longitudinal sarcoplasmic reticulum from heart muscle. J Biol Chem. 1988;263:10843-50.

44. Sharma MR, Penczek P, Grassucci R, Xin HB, Fleischer $\mathrm{S}$, Wagenknecht T. Cryoelectron microscopy and image analysis of the cardiac ryanodine receptor. J Biol Chem. 1998;273:18429-34.

45. Franzini-Armstrong C, Protasi F, Ramesh V. Shape, size, and distribution of $\mathrm{Ca}(2+)$ release units and couplons in skeletal and cardiac muscles. Biophys J. 1999;77:1528-39.

46. Sobie EA, Guatimosim S, Gomez-Viquez L, Song LS, Hartmann $\mathrm{H}$, Saleet Jafri $\mathrm{M}$, et al. The $\mathrm{Ca}^{2+}$ leak paradox and rogue ryanodine receptors: SR $\mathrm{Ca}^{2+}$ efflux theory and practice. Prog Biophys Mol Biol. 2006;90:172-85.

47. Cheng H, Lederer WJ. Calcium sparks. Physiol Rev. 2008;88:1491-545.

48. Xie W, Brochet DX, Wei S, Wang X, Cheng H. Deciphering ryanodine receptor array operation in cardiac myocytes. J Gen Physiol. 2010;136:129-33.

49. Brochet DX, Xie W, Yang D, Cheng H, Lederer WJ. Quarky calcium release in the heart. Circ Res. 2011;108:210-8.

50. Berlin JR, Cannell MB, Lederer WJ. Cellular origins of the transient inward current in cardiac myocytes. Role of fluctuations and waves of elevated intracellular calcium. Circ Res. 1989;65:115-26.

51. Venetucci LA, Trafford AW, O'Neill SC, Eisner DA. Na/Ca exchange: Regulator of intracellular calcium and source of arrhythmias in the heart. Ann N Y Acad Sci. 2007;1099:315-25.

52. Bovo E, Mazurek SR, Blatter LA, Zima AV. Regulation of sarcoplasmic reticulum $\mathrm{Ca}(2+)$ leak by cytosolic $\mathrm{Ca}(2+)$ in rabbit ventricular myocytes. J Physiol. 2011;589:6039-50.

53. Jiang $D$, Wang $R$, Xiao $B$, Kong $H$, Hunt DJ, Choi $P$, et al. Enhanced store overload-induced $\mathrm{Ca}^{2+}$ release and channel sensitivity to luminal $\mathrm{Ca}^{2+}$ activation are common defects of RyR2 mutations linked to ventricular tachycardia and sudden death. Circ Res. 2005;97:1173-81.

54. Belevych AE, Radwanski PB, Carnes CA, Györke S. 'Ryanopathy': Causes and manifestations of RyR2 dysfunction in heart failure. Cardiovasc Res. 2013;98:240-7.

55. Keizer J, Smith GD, Ponce-Dawson S, Pearson JE. Saltatory propagation of $\mathrm{Ca}^{2+}$ waves by $\mathrm{Ca}^{2+}$ sparks. Biophys $\mathrm{J}$. 1998;75:595-600.

56. Galimberti ES, Knollmann BC. Efficacy and potency of class I antiarrhythmic drugs for suppression of $\mathrm{Ca}^{2+}$ waves in 
permeabilized myocytes lacking calsequestrin. J Mol Cell Cardiol. 2011;51:760-8.

57. Fernandez-Velasco M, Gomez A, Benitah JP, Neco P. Ryanodine receptor channelopathies: The new kid in the arrhythmia neighbourhood. En: Yamada T, editor. Tachycardia. 1st ed. InTech; 2012. p. 65-88.

58. Eisner DA, Kashimura T, Venetucci LA, Trafford AW. From the ryanodine receptor to cardiac arrhythmias. Circ J. 2009;73:1561-7.

59. Hansford RG, Lakatta EG. Ryanodine releases calcium from sarcoplasmic reticulum in calcium-tolerant rat cardiac myocytes. J Physiol. 1987;390:453-67.

60. Urthaler F, Walker AA, Reeves RC, Hefner LL. Effects of ryanodine on contractile performance of intact length-clamped papillary muscle. Circ Res. 1989;65:1270-82.

61. Yamazawa T, Takeshima H, Sakurai T, Endo M, lino $M$. Subtype specificity of the ryanodine receptor for $\mathrm{Ca} 2+$ signal amplification in excitation-contraction coupling. EMBO J. 1996;15:6172-7.

62. Takeshima H, Komazaki S, Hirose K, Nishi M, Noda T, lino M. Embryonic lethality and abnormal cardiac myocytes in mice lacking ryanodine receptor type 2. EMBO J. 1998;17:3309-16.

63. Negretti N, O'Neill SC, Eisner DA. The effects of inhibitors of sarcoplasmic reticulum function on the systolic $\mathrm{Ca}^{2+}$ transient in rat ventricular myocytes. J Physiol. 1993;468:35-52.

64. Zima AV, Bovo E, Bers DM, Blatter LA. Ca2+ spark-dependent and -independent sarcoplasmic reticulum $\mathrm{Ca} 2+$ leak in normal and failing rabbit ventricular myocytes. J Physiol. 2010;588:3309-57.

65. Lukyanenko V, Viatchenko-Karpinski S, Smirnov A, Wiesner TF, Györke S. Dynamic regulation of sarcoplasmic reticulum $\mathrm{Ca}(2+)$ content and release by luminal $\mathrm{Ca}(2+)$-sensitive leak in rat ventricular myocytes. Biophys J. 2001;81:785-98.

66. Marks AR. Calcium cycling proteins and heart failure: mechanisms and therapeutics. J Clin Invest. 2013;123:46-52.

67. Priori SG, Napolitano C, Tiso N, Memmi M, Vignati G, Bloise $\mathrm{R}$, et al. Mutations in the cardiac ryanodine receptor gene (hRyR2) underlie catecholaminergic polymorphic ventricular tachycardia. Circulation. 2001;103:196-200.

68. Laitinen PJ, Brown KM, Piippo K, Swan H, Devaney JM, Brahmbhatt $\mathrm{B}$, et al. Mutations of the cardiac ryanodine receptor (RyR2) gene in familial polymorphic ventricular tachycardia. Circulation. 2001;103:485-90.

69. Tiso N, Stephan DA, Nava A, Bagattin A, Devaney JM, Stanchi $F$, et al. Identification of mutations in the cardiac ryanodine receptor gene in families affected with arrhythmogenic right ventricular cardiomyopathy type 2 (ARVD2). Hum Mol Genet. 2001;10:189-94.

70. Napolitano C, Wilson J. Genetic mutations and inherited arrhythmias [consultado 20 Feb 2014]. Disponible en: http: //www.fsm.it/cardmoc/

71. Leenhardt A, Lucet V, Denjoy I, Grau F, Ngoc DD, Coumel P. Catecholaminergic polymorphic ventricular tachycardia in children. A 7-year follow-up of 21 patients. Circulation. 1995;91:1512-9.

72. Cerrone M, Napolitano C, Priori SG. Catecholaminergic polymorphic ventricular tachycardia: A paradigm to understand mechanisms of arrhythmias associated to impaired $\mathrm{Ca}(2+)$ regulation. Heart Rhythm. 2009;6:1512-9.

73. Cerrone M, Colombi B, Santoro M, di Barletta MR, Scelsi M, Villani L, et al. Bidirectional ventricular tachycardia and fibrillation elicited in a knock-in mouse model carrier of a mutation in the cardiac ryanodine receptor. Circ Res. 2005;96:e77-82.

74. Loaiza R, Benkusky NA, Powers PP, Hacker T, Noujaim S, Ackerman MJ, et al. Heterogeneity of ryanodine receptor dysfunction in a mouse model of catecholaminergic polymorphic ventricular tachycardia. Circ Res. 2013;112:298-308.
75. Shannon TR, Pogwizd SM, Bers DM. Elevated sarcoplasmic reticulum $\mathrm{Ca}^{2+}$ leak in intact ventricular myocytes from rabbits in heart failure. Circ Res. 2003;93:592-4.

76. Kubalova Z, Terentyev D, Viatchenko-Karpinski S, Nishijima Y, Györke I, Terentyeva R, et al. Abnormal intrastore calcium signaling in chronic heart failure. Proc Natl Acad Sci U S A. 2005;102:14104-9.

77. Lindner M, Brandt MC, Sauer H, Hescheler J, Böhle T, Beuckelmann DJ. Calcium sparks in human ventricular cardiomyocytes from patients with terminal heart failure. Cell Calcium. 2002;31:175-82.

78. Li Y, Kranias EG, Mignery GA, Bers DM. Protein kinase A phosphorylation of the ryanodine receptor does not affect calcium sparks in mouse ventricular myocytes. Circ Res. 2002;90:309-16.

79. Benkusky NA, Weber CS, Scherman JA, Farrell EF, Hacker TA, John MC, et al. Intact beta-adrenergic response and unmodified progression toward heart failure in mice with genetic ablation of a major protein kinase A phosphorylation site in the cardiac ryanodine receptor. Circ Res. 2007;101:819-29.

80. MacDonnell SM, García-Rivas G, Scherman JA, Kubo H, Chen X, Valdivia $\mathrm{H}$, et al. Adrenergic regulation of cardiac contractility does not involve phosphorylation of the cardiac ryanodine receptor at serine 2808. Circ Res. 2008;102:e65-72.

81. Pereira L, Cheng H, Lao DH, Na L, van Oort RJ, Brown JH, et al. Epac2 mediates cardiac $\beta 1$-adrenergic-dependent sarcoplasmic reticulum $\mathrm{Ca}^{2+}$ leak and arrhythmia. Circulation. 2013;127:913-22.

82. Van Oort RJ, McCauley MD, Dixit SS, Pereira L, Yang Y, Respress JL, et al. Ryanodine receptor phosphorylation by calcium/calmodulin-dependent protein kinase II promotes life-threatening ventricular arrhythmias in mice with heart failure. Circulation. 2010;122:2669-79.

83. McCauley MD, Wehrens XH. Targeting ryanodine receptors for anti-arrhythmic therapy. Acta Pharmacol Sin. 2011;32:749-57.

84. Zhang SJ, Liu ZH, Zou C, Wang L. Effect of metoprolol on sarcoplasmic reticulum $\mathrm{Ca}^{2+}$ leak in a rabbit model of heart failure. Chin Med J. 2012;125:815-22.

85. Mochizuki M, Yano M, Oda T, Tateishi H, Kobayashi S, Yamamoto $T$, et al. Scavenging free radicals by low-dose carvedilol prevents redox-dependent $\mathrm{Ca} 2+$ leak via stabilization of ryanodine receptor in heart failure. J Am Coll Cardiol. 2007;49:1722-32.

86. Kobayashi S, Yano M, Suetomi T, Ono M, Tateishi H, Mochizuki $M$, et al. Dantrolene, a therapeutic agent for malignant hyperthermia, markedly improves the function of failing cardiomyocytes by stabilizing interdomain interactions within the ryanodine receptor. J Am Coll Cardiol. 2009;53:1993-2005.

87. Kobayashi S, Yano M, Uchinoumi H, Suetomi T, Susa T, Ono M, et al. Dantrolene, a therapeutic agent for malignant hyperthermia, inhibits catecholaminergic polymorphic ventricular tachycardia in a RyR2(R2474S/+) knock-in mouse model. Circ J. 2010;74:2579-84.

88. Maxwell JT, Domeier TL, Blatter LA. Dantrolene prevents arrhythmogenic $\mathrm{Ca}^{2+}$ release in heart failure. Am J Physiol Heart Circ Physiol. 2012;302:H953-63.

89. Lehnart SE, Wehrens XH, Laitinen PJ, Reiken SR, Deng SX, Cheng $Z$, et al. Sudden death in familial polymorphic ventricular tachycardia associated with calcium release channel (ryanodine receptor) leak. Circulation. 2004;109:3208-14.

90. Lehnart SE, Terrenoire C, Reiken S, Wehrens XH, Song LS, Tillman EJ, et al. Stabilization of cardiac ryanodine receptor prevents intracellular calcium leak and arrhythmias. Proc Natl Acad Sci U S A. 2006;103:7906-10.

91. Hunt DJ, Jones PP, Wang R, Chen W, Bolstad J, Chen $K<E T$ $\mathrm{AL}>$. K201 (JTV519) suppresses spontaneous $\mathrm{Ca}^{2+}$ release and $\left[{ }^{3} \mathrm{H}\right]$ ryanodine binding to RyR2 irrespective of FKBP12.6 association. Biochem J. 2007;404:431-8. 
92. Sacherer M, Sedej S, Wakuła P, Wallner M, Vos MA, Kockskämper J, et al. JTV519 (K201) reduces sarcoplasmic reticulum $\mathrm{Ca}^{2+}$ leak and improves diastolic function in vitro in murine and human non-failing myocardium. $\mathrm{Br} \mathrm{J}$ Pharmacol. 2012; 167:493-504.

93. Hilliard FA, Steele DS, Laver D, Yang Z, le Marchand SJ, Chopra $\mathrm{N}$, et al. Flecainide inhibits arrhythmogenic $\mathrm{Ca}^{2+}$ waves by open state block of ryanodine receptor $\mathrm{Ca}^{2+}$ release channels and reduction of $\mathrm{Ca}^{2+}$ spark mass. J Mol Cell Cardiol. 2010;48:293-301.

94. Watanabe H, Chopra N, Laver D, Hwang HS, Davies SS, Roach $\mathrm{DE}$, et al. Flecainide prevents catecholaminergic polymorphic ventricular tachycardia in mice and humans. Nat Med. 2009;15:380-3.

95. Sikkel MB, Collins TP, Rowlands C, Shah M, O'Gara P, Williams $\mathrm{AJ}$, et al. Flecainide reduces $\mathrm{Ca}(2+)$ spark and wave frequency via inhibition of the sarcolemmal sodium current. Cardiovasc Res. 2013;98:286-96.

96. Jiang X, Liu W, Deng J, Lan L, Xue X, Zhang C, et al. Polydatin protects cardiac function against burn injury by inhibiting sarcoplasmic reticulum $\mathrm{Ca}(2+)$ leak by reducing oxidative modification of ryanodine receptors. Free Radic Biol Med. 2013;60:292-9.
97. Wehrens XH, Lehnart SE, Reiken SR, Deng SX, Vest JA, Cervantes $D$, et al. Protection from cardiac arrhythmia through ryanodine receptor-stabilizing protein calstabin2. Science. 2004;304:292-6

98. Liu N, Colombi B, Memmi M, Zissimopoulos S, Rizzi N, Negri $\mathrm{S}$, et al. Arrhythmogenesis in catecholaminergic polymorphic ventricular tachycardia: Insights from a RyR2 R4496C knock-in mouse model. Circ Res. 2006;99:292-8.

99. Kimura J, Kawahara M, Sakai E, Yatabe J, Nakanishi H. Effects of a novel cardioprotective drug, JTV-519, on membrane currents of guinea pig ventricular myocytes. Jpn J Pharmacol. 1999;79:275-81.

100. Nakaya H, Furusawa Y, Ogura T, Tamagawa M, Uemura H. Inhibitory effects of JTV-519, a novel cardioprotective drug, on potassium currents and experimental atrial fibrillation in guinea-pig hearts. $\mathrm{Br} \mathrm{J}$ Pharmacol. 2000;131: 1363-72.

101. Aschar-Sobbi R, Emmett TL, Kargacin GJ, Kargacin ME. Phospholamban phosphorylation increases the passive calcium leak from cardiac sarcoplasmic reticulum. Pflugers Arch. 2012;464:295-305. 